
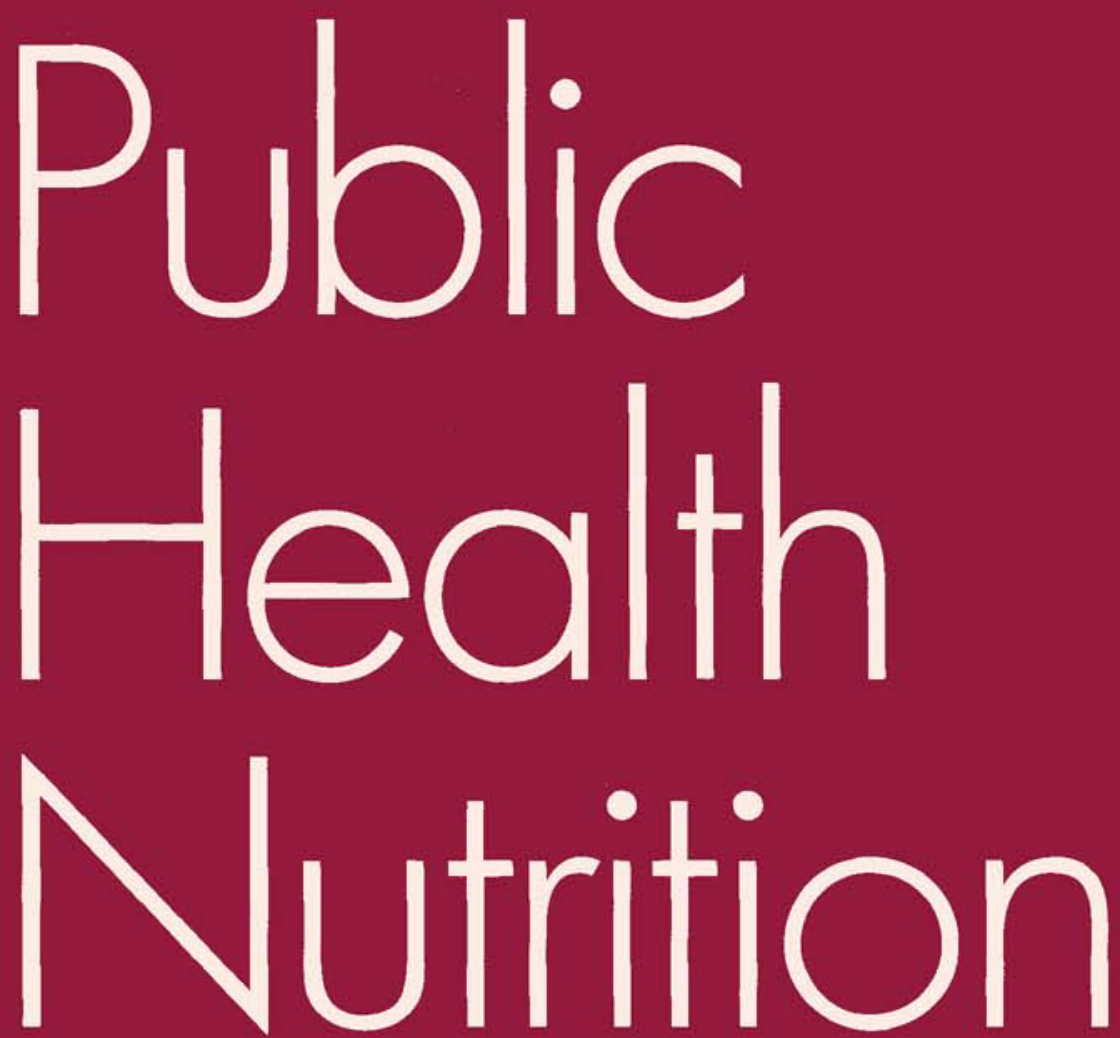

An international journal published on behalf of The Nutrition Society by CAB INTERNATIONAL 


\section{Public Health Nutrition}

Volume 1, 1998 ISSN: 1368-9800

Published quarterly

\section{Aims and Scope}

Public Health Nutrition is an international, peer-reviewed journal publishing original research papers, topical review articless, Letters to the Editors, editorials and invited commentaries, and book reviews. The journal offers a population based approach to the practical application of research findings and provides a timely vehicle for lively discussion.

\section{Topics covered include:}

- Nutritional epidemiology - studies relating nutrition to health or disease risk

- Nutrition related health promotion

- Evaluation of effectiveness of intervention studies aimed at improving health

- Role of nutrition in high risk and vulnerable groups

- Development of research methods, validation of measures, calibration

- Population based research related to primary prevention of illness

Public Health Nutrition will publish occasional Special and Supplementary issues. These will focus on topics of major interest.

The contents page and abstracts from this journal are available on the Internet before publication at: http://www.cabi.org/

\section{International Editorial Board}

\section{Editors}

Dr Barrie Margetts (Editor-in-Chief)

Institute of Human Nutrition

Southampton

$U K$

Fax: $+44(0) 1703796529$

Email: phn@soton.ac.uk

Dr Michael Nelson

Kings College London

University of London, UK
Professor Lenore Kohlmeier (Editor for North America) Schools of Public Health and Medicine

University of North Carolina at Chapel Hill

Chapel Hill, USA

Fax: + 1 (919) 9662089

Email: LenoreK@unc.edu

Professor Frans Kok

Wageningen Agricultural University

The Netherlands

\section{Associate Editors}

Dr Faruk Ahmed

University of Dhaka

Bangladesh

Dr Annic Anderson

University of Dundee, UK

Dr Tim Cole

MRC Dunn Nutrition Centre, $U K$

Dr Ian Darnton-Hill

OMNI, USA

Dr Kerin O'Dea

Deakin University, Australia
Dr Pirjo Pietinen

National Public Health Institute,

Finland

Dr John Potter

Fred Hutchinson Cancer

Research Center, USA

Dr Shoba Rao

Agharkar Research Institute,

India

Dr Elio Riboli

International Agency for

Research on Cancer, France
Dr Prakash Shetty

London School of Hygiene and Tropical Medicine, UK

Dr Nelia Steyn

University of the North, South Africa

Dr Susan Walker University of the West Indies, Jamaica

Ms Agneta Yngve

Karolinska Institute, Sweden

The Nutrition Society

The society has as its objective the advancement of the scientific study of nutrition and its application to the maintenance of human and animal health.

Particulars of The Nutrition Society and application forms for membership are available from the Honorary Secretary, The Nutrition Society, 10 Cambridge Court, 210 Shepherds Bush Road, London W6 7NJ, UK.

Telephone: +44 (0)171 371 6225, Fax: +44 (0)1716021756

The Nutrition Society home page is at http://www.nutsoc.org.uk/ 